8. Singer AJ, Ardise J, Gulla J, Cangro J. Point-of-care testing reduces length of stay in emergency department chest pain patients. Ann Emerg Med 2005;45:587-91.

9. Zarich S, Bradley K, Seymour J, Ghali W, Traboulsi A, Mayall ID, et al. Impact of troponin T determinations on hospital resource utilization and costs in the evaluation of patients with suspected myocardial ischemia. Am J Cardiol 2001;88:732-6.

10. Laurence C, Gialamas A, Yelland L, Bubner T, Ryan P, Willson K; the PoCT Trial Management Committee. A pragmatic cluster randomised controlled trial to evaluate the safety, clinical effectiveness, cost effectiveness and satisfaction with point of care testing in a general practice setting - rationale, design and baseline characteristics. Trials 2008;9:50.

11. Bubner TK, Laurence CO, Gialamas A, Yelland LN, Ryan $P$, Willson KJ, et al. Effectiveness of point-of-care testing for therapeutic control of chronic conditions: results from the PoCT in General Practice Trial. Med J Aust 2009;190:624-6.
12. Gialamas $A$, Yelland LN, Ryan $P$, Willson $K$, Laurence CO, Bubner TK, et al. Does point-of-care testing lead to the same or better adherence to medication? A randomised controlled trial: the PoCT in General Practice Trial. Med J Aust 2009;191:487-91.

13. Shephard MD, Mazzachi BC, Watkinson L, Shephard AK, Laurence $C$, Gialamas A, et al. Evaluation of a training program for device operators in the Australian Government's Point of Care Testing in General Practice Trial: issues and implications for rural and remote practices. Rural Remote Health 2009;9:1189. Epub 2009 Aug 10.

\section{Further reading}

Price CP, St John A, editors. Point-of-care testing for managers and policymakers: from rapid testing to better outcomes. Washington, DC: AACC Press; 2006.

\title{
Adverse reactions and Australian Prescriber : back to the future
}

John S Dowden, Editor-in-Chief, Australian Prescriber

The Australian Adverse Drug Reactions Bulletin was first published in $1974 .{ }^{1}$ This monthly publication became colloquially known as the ADRAC Bulletin as its content was determined by the Adverse Drug Reactions Advisory Committee.

In 1975 Australian Prescriber was launched and the ADRAC Bulletin was incorporated into it. There was some initial disquiet about the merger as the rate of reporting of adverse drug reactions reduced. This fall may have reflected the change from monthly to quarterly publication of the Bulletin. ${ }^{2}$

The Adverse Drug Reactions section was a regular feature of Australian Prescriber until 1982, when the publication of the journal was temporarily suspended. ${ }^{3}$ The Bulletin then resumed its existence as a separate publication. It remained separate when the publication of Australian Prescriber restarted in 1983.

Both publications were distributed using a government mailing list, but an Australian Prescriber survey in 1989 found that more than $25 \%$ of respondents were not receiving the publications. ${ }^{4}$ This problem was mentioned in the Baume review of drug evaluation in 1991. The review recommended that the mailing list should contain at least all medical practitioners, pharmacists and dentists. This was because the Bulletin was recognised as the major means of informing health professionals about the analysis of adverse drug reaction reports. ${ }^{5}$

Shortly after the Baume review a decision was made to distribute the Bulletin in the same package as Australian Prescriber. Although there were concerns that this could affect the rate of reporting of adverse reactions, the joint mailing went ahead. This arrangement has continued until now, despite Australian Prescriber moving publishers. ${ }^{3}$ In 1999 Australian Prescriber increased publication to six issues per year and the Bulletin followed in 2003.

From 2010, information about adverse reactions will once again be included in a special section of Australian Prescriber. Medicines Safety Update will be prepared by the production team of the former ADRAC Bulletin under the guidance of the new Office of Medicines Safety Monitoring (OMSM). As the electronic version of Australian Prescriber has many overseas readers, the new arrangements will deliver important information about adverse reactions to a wider audience.

Australian Prescriber is pleased to be part of the new direction for informing health professionals about adverse reactions to medicines.

\section{References}

1. McEwen J. A history of therapeutic goods regulation in Australia. Canberra: Commonwealth of Australia; 2007.

2. Adverse Drug Reactions Advisory Committee. Have you reported an adverse drug reaction recently? Aust Prescr 1976;1:77-8.

3. Dowden JS. Australian Prescriber - the first 30 years. Aust Prescr 2005;28:120-2.

4. Saltman DC, Mant A. Readership survey: What you think of Australian Prescriber. Aust Prescr 1990;13:47-8.

5. Baume P. A question of balance. Report on the future of drug evaluation in Australia. Canberra: Australian Government Publishing Service; 1991. 